\title{
EMBRIOTOXIC EFFECTS OF MATERNAL EXPOSURE TO Tityus serrulatus SCORPION VENOM
}

\author{
BARÃO A. A. S. (1, 2), NENCIONI A. L. A. (1), DORCE V. A. C. (1)
}

(1) Laboratory of Pharmacology, Butantan Institute, São Paulo, São Paulo State, Brazil; (2) Center for Disease Control, SES, São Paulo, São Paulo State, Brazil.

\begin{abstract}
Tityus serrulatus is the most venomous scorpion in Brazil; however, it is not known whether its venom causes any harm to the offspring whose mothers have received it. This study investigates whether the venom of $T$. serrulatus may lead to deleterious effects in the offspring, when once administered to pregnant rats at a dose that causes moderate envenomation $(3 \mathrm{mg} / \mathrm{kg})$. The venom effects were studied on the $5^{\text {th }}$ and on the $10^{\text {th }}$ gestation day (GD5 and GD10). The maternal reproductive parameters of the group that received the venom on GD5 showed no alteration. The group that received the venom on GD10 presented an increase in post-implantation losses. In this group, an increase in the liver weight was also observed and one-third of the fetuses presented incomplete ossification of skull bones. None of the groups that received the venom had any visceral malformation or delay in the fetal development of their offspring. The histopathological analysis revealed not only placentas and lungs but also hearts, livers and kidneys in perfect state. Even having caused little effect on the dams, the venom may act in a more incisive way on the offspring, whether by stress generation or by a direct action.
\end{abstract}

KEY WORDS: scorpion venom, perinatal, Tityus serrulatus, pregnancy, embryofetotoxicity.

CONFLICTS OF INTEREST: There is no conflict.

\section{CORRESPONDENCE TO:}

VALQUIRIA ABRÃO CORONADO DORCE, Laboratory of Pharmacology, Butantan Institute, Av. Dr. Vital Brasil, 1500, 05503-900, São Paulo, SP, Brazil. Phone: 5511 37267222 Extension 2133. Fax: + 55113726 1505. Email: vdorce@butantan.gov.br. 


\section{INTRODUCTION}

Scorpions are dangerous animals distributed around the world. Species causing human envenomation belong to the Buthidae family (18). The envenomation is characterized by intense local pain and in some cases by systemic effects. These include lung edema partially due to severe cardiovascular alterations and catecholamines and kinins release increasing the pulmonary vascular permeability; complex respiratory arrhythmias such as tachypnea, hyperpnea, periodic respiration and respiratory paralysis, explained mainly by stimulation of afferent visceral receptors, being reflex in nature (11) or alternatively due to actions of the venom on the central nervous system $(10,32)$.

Scorpion venoms contain a large number of bioactive components. Several of the long-chain peptides were shown to be responsible for neurotoxic effects. These toxins are basic polypeptides with molecular weights of approximately 7,000, without enzymatic action (7) and have been shown to affect the ion permeability of excitable cells. Each scorpion venom has many neurotoxins $(7,25,36)$ whose mechanism of action has been extensively studied using both crude venom and purified toxins. A great number of the described effects may be explained by neurotransmitter release from synapses resulting from an excitatory effect in axonal membranes $(16,27)$. A large number of scorpion neurotoxins are specifically able to modify the normal function of sodium channels $(6,7,16,29)$. Other scorpion toxins act by blocking potassium channels $(2,5,28)$.

In the early nineties, reports of severe envenomation by scorpion stings have shown an alarming increase in various tropical and subtropical countries. In Brazil, more than 30,000 scorpion stings, resulting in more than 100 deaths, have been reported over a five-year period (17).

Tityus serrulatus and Tityus bahiensis are the most venomous scorpion species existent in Brazil, where they are responsible for the largest number of stings (37). Considering the limited quantities of venom that a scorpion can inject, and the dramatic clinical findings that may result after a single sting, it is obvious that the scorpion venom has high active components $(25,27)$.

Human activity leading to an increase in trash and waste attracts insects and spiders, the main prey of scorpions, and the possibility of occupancy of niches inside human dwellings causes an overlapping of the human and scorpion populations increasing 
the probability of incidents (17). Thus, there is the possibility of envenomation of pregnant women.

Although there are several studies concerning the effects and the mechanism of action of the venoms and their toxins, it is not known whether they cause any harm to the offspring whose mothers have received this venom either accidentally or experimentally. Only few studies are reported in literature. Osman et al. (24) showed that the venom of the scorpion Leiurus quinquestriatus produced a marked increase in the frequency and amplitude of contraction of the uterus. The release of kinins was pointed as responsible for this effect. Ismail and colleagues (13) administered repeated injections of Androctonus amoreuxi venom to female rats during 5 or 8 successive gestational days and they have found out a high fetal resorption rate; ossification defects and weight losses were also observed in many of the viable fetuses.

This study was designed to investigate whether the venom of the scorpion $T$. serrulatus administered once to pregnant female rats in a dose which causes a moderate envenomation may lead to deleterious effects in their offspring.

\section{MATERIALS AND METHODS}

\section{Animals and Treatment}

Male and female Wistar rats, weighed 250-270g, about 90 days old, housed under controlled temperature $\left(20 \pm 2^{\circ} \mathrm{C}\right)$, with a $12: 12$ dark:light schedule and free access to food and water, were used. After acclimatization for one week, two female rats were placed together with one male in the afternoon. In the morning of the following day, females showing evidence of mating (vaginal plug or vaginal smear with sperm cells) were assigned in rotation to each group. The day on which there was evidence of mating was recorded as gestation day 0 (GD0). During gestation, two dams were housed per plastic cage measuring $40 \times 50 \times 20 \mathrm{~cm}$ and covered with metal lids. Dams were treated subcutaneously with 0.0 or $3.0 \mathrm{mg} / \mathrm{kg}$ of venom on GD5 or on GD10.

The venom was obtained by the Laboratory of Arthropods (Butantan Institute) from mature $T$. serrulatus scorpions by electrical stimulation of the telson and supplied by the Venom Commission of the Butantan Institute. It was lyophilized immediately after extraction and dissolved in $\mathrm{NaCl} 0.9 \%$ before use.

These experiments followed the guidelines of the Bioethics Commission of the Butantan Institute of São Paulo, Brazil. 


\section{Experimental Design}

On GD21, females were deeply anesthetized with ether and subjected to laparotomy for ovaries and uterus section. The gravid uterus was weighed. The uterine horns were cut; the fetuses and their placenta were removed, weighed and examined for gross abnormalities. The number of implantation sites, resorptions, dead and alive fetuses was recorded in both uterine horns. The ovaries were dissected and the number of corpora lutea was recorded. The pre- and post-implantation losses were calculated (pre-implantation loss $=$ number of corpora lutea - number of implantations I number of corpora lutea; post-implantation loss = number of implantations - number of live fetuses / number of implantations). After euthanasia, half of each litter was fixed in Bouin's solution for subsequent visceral examination by the serial section method of Wilson (38) and the other half litter was eviscerated, fixed in 70\% ethanol, cleared with potassium chloride and stained with Alizarin red by the technique of Staples and Schenell (34). The extent of ossification was evaluated using the parameters proposed by Aliverti et al. (1). The kidneys, the liver, the lungs and the heart of the fetuses used for ossification evaluation were individually weighed. The lungs, liver, kidneys, heart and placenta of a sample of fetuses were removed, stored in formalin for at least one week, and embedded in Paraplast ${ }^{\circledR}$. Sections of $5 \mu \mathrm{m}$ were mounted on a glass slide and stained with hematoxylin/eosin and histologically evaluated.

\section{Statistical Analysis}

For maternal reproductive parameters (number of implants, corpora lutea, resorptions, live fetuses, dead fetuses, pre-implantation loss and post-implantation loss) and the data on body or organ weight were analyzed by ANOVA followed by the Tukey-Kramer test. Skeletal and visceral anomalies and number of ossification centers were evaluated by the Fisher's exact test. The significance level for all tests was set at $p<0.05$.

\section{RESULTS}

Dams that received venom $(3.0 \mathrm{mg} / \mathrm{kg})$ on GD5 or GD10 had no apparent signs of toxicosis during pregnancy and gained as much weight as control ones (Figure 1). 


\section{Effects of Tityus serrulatus Venom on the Offspring of GD5 Treated Dams}

Concerning the reproductive parameters of the dams as well as the weight of their uterus (Table 1), placentas and offspring (Table 2), the results obtained with the venom showed no significant difference between control and experimental groups.

There were no cases of anomaly or external malformation (Table 3). Also, no visceral and skeletal malformations were observed (Table 3). The presence of anomalies in the skeleton and viscera of both control and experimental groups was relatively common. The results obtained in the counting of the ossification centers of the offspring showed that there were no significant differences between the experimental groups and their control groups.

In the histological analyses of placentas, livers, kidneys, hearts and lungs of the offspring from the group that received the venom and its respective control group, tissues with no alterations and with completely normal appearance were verified, as it was expected for healthy newborns. However, the weight of the liver from fetuses of the experimental group showed an increase (Table 2).

\section{Effects of Tityus serrulatus Venom on the Offspring of GD10 Treated Dams}

Concerning the reproductive parameters of the dams treated with venom as well as the weight of their uterus (Table 1), placentas and offspring (Table 2), the results obtained with the venom showed no significant difference between control and experimental groups. However, there was an increase in post-implantation losses (Table 1).

Offspring malformations and external anomalies at birth (Table 3) did not occur. In relation to the visceral analyses (Table 3), only a small number of anomalies occurred in both groups. With none of the doses, there were significant differences between groups.

In relation to skeleton malformations (Table 3), the data were similar to those observed in the offspring treated at GD5. Also, no significant difference in the number of ossification centers was observed between groups. However, incomplete ossification of skull bones was observed.

In histological analyses of placentas, livers, kidneys, hearts and lungs of the offspring from the group that received the venom and its respective control group, no alterations were detected. The weight of the liver of fetuses from the experimental group, however, showed an increase (Table 2). 


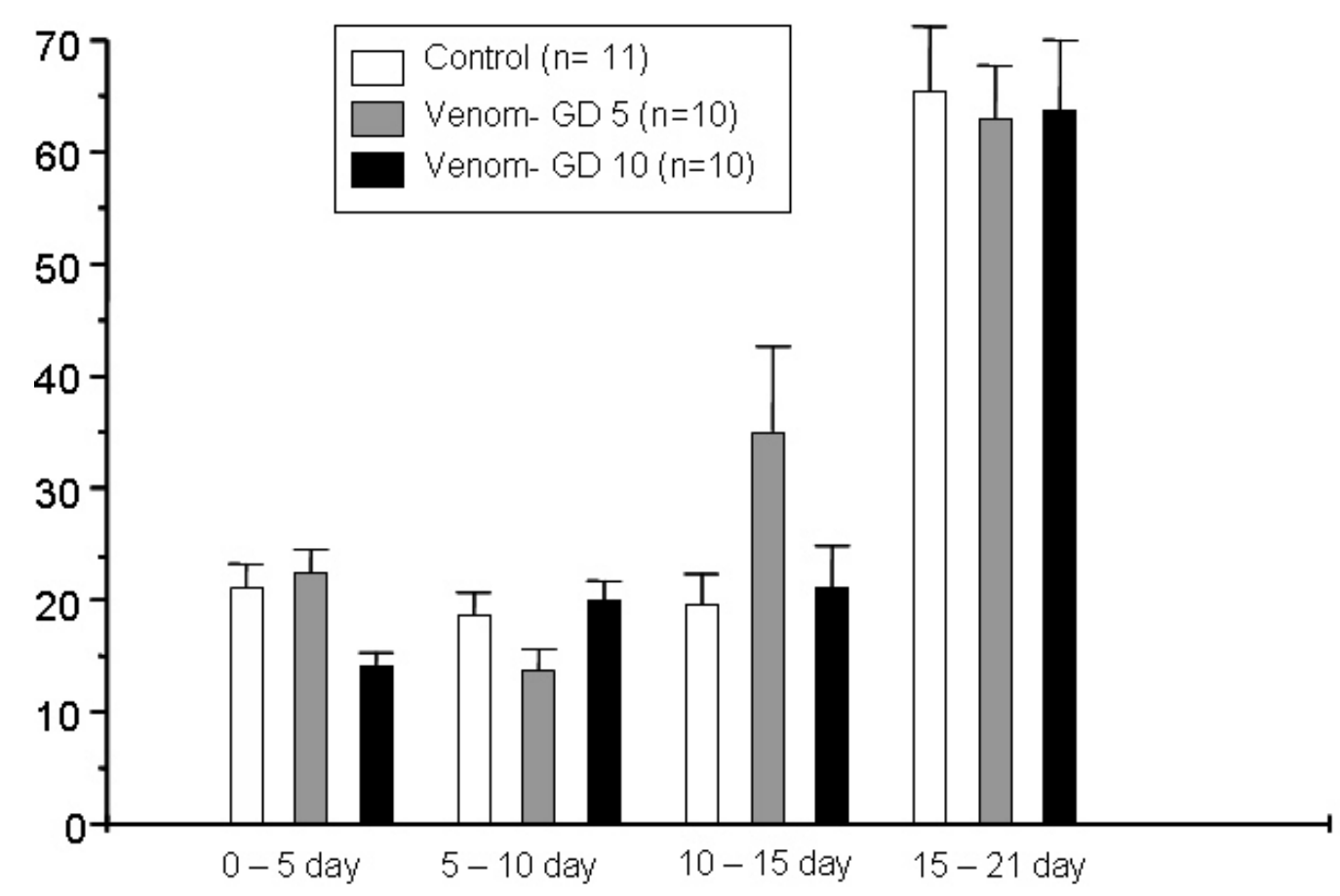

Figure 1. Maternal weight gain, in grams, of rats treated with Tityus serrulatus venom, $3.0 \mathrm{mg} / \mathrm{kg}$, on the $5^{\text {th }}$ and on the $10^{\text {th }}$ gestation day (GD). Values represent the mean \pm SEM. $n=$ Number of dams. No significant difference among groups was observed.

Table 1. Reproductive parameters of pregnant rats treated with Tityus serrulatus venom, $3.0 \mathrm{mg} / \mathrm{kg}$, on the $5^{\text {th }}$ and on the $10^{\text {th }}$ gestation day (GD).

\begin{tabular}{lccc}
\hline Parameters & $\begin{array}{c}\text { Control } \\
\mathbf{( n = 1 1 )}\end{array}$ & $\begin{array}{c}\text { Venom on GD5 } \\
\mathbf{( n = 1 0 )}\end{array}$ & $\begin{array}{c}\text { Venom on GD10 } \\
(\mathbf{n}=\mathbf{1 0})\end{array}$ \\
\hline Early resorptions/dam & $0.36 \pm 0.20$ & $0.20 \pm 0.13$ & $0.20 \pm 0.13$ \\
Implantations/dam & $9.45 \pm 1.12$ & $12.20 \pm 0.76$ & $11.20 \pm 0.94$ \\
Corpora lutea/dam & $12.27 \pm 0.67$ & $13.60 \pm 0.67$ & $12.60 \pm 0.37$ \\
Pre-implantation losses/dam & $0.26 \pm 0.08$ & $0.13 \pm 0.03$ & $0.15 \pm 0.07$ \\
Post-implantation losses/dam & $0.00 \pm 0.00$ & $0.14 \pm 0.04$ & $0.15 \pm 0.06^{*}$ \\
Live fetuses/dam & $9.27 \pm 1.09$ & $11.70 \pm 0.75$ & $10.60 \pm 0.96$ \\
Dead fetuses/dam & $0.00 \pm 0.00$ & $1.40 \pm 0.95$ & $0.90 \pm 0.71$ \\
Uterus weight (in grams) & $68.1 \pm 7.5$ & $84.6 \pm 4.6$ & $77.7 \pm 6.3$ \\
\hline
\end{tabular}

Data are the mean \pm SD

* Significantly different from control, $p<0.05$, ANOVA followed by Tukey Kramer.

$\mathrm{n}=$ Number of dams. 
A. A. S. Barão et al. EMBRIOTOXIC EFFECTS OF MATERNAL EXPOSURE TO Tityus serrulatus SCORPION VENOM. J. Venom. Anim. Toxins incl. Trop. Dis., 2008, 14, 2, p. 328

Table 2. Weight of fetuses, placentas and some internal organs of fetuses of dams treated with Tityus serrulatus venom, $3.0 \mathrm{mg} / \mathrm{kg}$, on the $5^{\text {th }}$ and on the $10^{\text {th }}$ gestation day (GD).

\begin{tabular}{ccccccc}
\hline Weight (in grams) & Control & $\mathbf{n}$ & Venom GD5 & $\mathbf{n}$ & Venom GD10 & $\mathbf{n}$ \\
\hline Fetuses & $5.4 \pm 0.3$ & 107 & $5.1 \pm 0.1$ & 120 & $5.2 \pm 0.4$ & 106 \\
Placentas & $0.6 \pm 0.0$ & 107 & $0.6 \pm 0.0$ & 120 & $0.6 \pm 0.0$ & 106 \\
Liver & $0.29+0.01$ & 37 & $0.41+0.02^{*}$ & 32 & $0.40+0.01^{*}$ & 37 \\
Lung & $0.10+0.00$ & 37 & $0.14+0.02$ & 31 & $0.12+0.00$ & 37 \\
Heart & $0.04+0.01$ & 34 & $0.03+0.00$ & 32 & $0.03+0.00$ & 37 \\
Kidney** & $0.04+0.00$ & 37 & $0.04+0.00$ & 32 & $0.04+0.00$ & 36 \\
\hline
\end{tabular}

Data are the mean \pm SD

* Significantly different from control, $\mathrm{p}<0.05$, ANOVA followed by Tukey Kramer.

$\mathrm{n}=$ Number of fetuses

** Kidneys were weighed in pairs 
Table 3. Skeletal and visceral malformations or anomalies of fetuses of dams treated with Tityus serrulatus venom, $3.0 \mathrm{mg} / \mathrm{kg}$, on the $5^{\text {th }}$ and on the $10^{\text {th }}$ gestation day (GD).

\begin{tabular}{lccc}
\hline Parameters & Control & Venom GD5 & Venom GD10 \\
& $(n=10)$ & $(n=10)$ & $(n=10)$ \\
\hline
\end{tabular}

\section{External malformations}

$\begin{array}{llll}\text { Number of affected fetuses } & 0 / 23 & 0 / 35 & 0 / 25 \\ \text { Number of affected offspring } & 0 / 10 & 0 / 10 & 0 / 10\end{array}$

\section{External anomalies}

$\begin{array}{llll}\text { Number of affected fetuses } & 0 / 23 & 0 / 35 & 0 / 25 \\ \text { Number of affected offspring } & 0 / 10 & 0 / 10 & 0 / 10\end{array}$

\section{Skeletal malformations}

Number of affected fetuses

0/37

0/32

0/36

Number of affected offspring

$0 / 10$

$0 / 10$

$0 / 10$

\section{Skeletal anomalies}

Number of affected fetuses

$1 / 37$

$2 / 32$

$12 / 36^{*}$

Number of affected offspring

$1 / 10$

$2 / 10$

$6 / 10$

Incomplete ossification of skull

bones

$0 / 37$

$2 / 32$

$12 / 36^{*}$

Wavy ribs

$1 / 37$

$2 / 32$

$0 / 36$

Fused ribs

$0 / 37$

$0 / 32$

$0 / 36$

Shared vertebra

0/37

$0 / 32$

$0 / 36$

Rudimentary rib

$3 / 37$

$1 / 32$

$1 / 36$

\section{Visceral malformations}

Number of affected fetuses

$0 / 23$

0/35

$0 / 25$

Number of affected offspring

$0 / 10$

$0 / 10$

$0 / 10$

\section{Visceral anomalies}

\begin{tabular}{llll} 
Number of affected fetuses & $3 / 23$ & $5 / 35$ & $4 / 25$ \\
Number of affected offspring & $2 / 10$ & $4 / 10$ & $3 / 10$ \\
Cerebral hemorrhage & $3 / 23$ & $4 / 35$ & $4 / 25$ \\
\hline$n=$ Number of dams &
\end{tabular}

* Significantly different from control, $p<0.05$, Fisher's exact test. 


\section{DISCUSSION}

In rat development, GD5 corresponds to the end of the blastocyst implantation period in the uterus. Exposure to harmful substances in this period may lead to embryo lethality, being extremely rare the occurrence of teratogenesis. The GD10 coincides with the middle of the organogenesis period, which consists in a series of processes defined in a sequence and the formation of organs itself. Each organ in formation presents a period in which it is more susceptible to the agents; this is called the critical period. In rats, GD10 comprehends the critical periods for many organs, for instance: eyes, brain, heart and veins, skeleton system, urogenital system, etc. Substances administered during the organogenesis may lead to teratogenesis, when the lesions caused by them allow the survival of the affected individual, or to embryo lethality, if the lesion is not compatible with the possibility of the embryo survival.

There is an increasing probability of exposure of humans and pets to the venom of $T$. serrulatus during the gestational period considering the easy way in which this animal adapts and disseminates in completely urbanized environments. There are no data in literature on prenatal exposure to this venom. Therefore, in case a clinical situation occurs, there is no scientific support to help on an eventual intervention. Thus, the present work aimed at assessing possible toxic effects of this venom on the offspring in case the dam was the victim of such accident during gestation.

Only one venom dose was employed, once we tried to correlate our data with the natural conditions of envenomation. In fact, the accidents generally occur only once and the exposure to the venom was restricted.

A dose that simulated the effects of mild accident in pregnant rats was chosen (3.0 mg/kg), and the intoxication of the dam on a more serious level was deliberately avoided in order not to compromise any positive result. The dose was based on the $\mathrm{LD}_{50}$ for nonpregnant rats (33), which was previously calculated in our laboratory, administered once during two different periods of pregnancy to different groups of dams.

During the application, the venom may probably have caused some pain to the animals. Classic behavioral signals related to pain could be observed such as vocalization and attempt to run, which were not observed in the control animals. It seemed to disappear by the end of the application.

The action of $T$. serrulatus venom follows an "all or none" type of effect. This way, while some people, when injured, feel intense pain and present some minor effects 
such as a small alteration in the cardiac rhythm and an increase in secretion, others develop a large number of serious effects, even getting to convulsion and death (9, 12, 19).

Some data in literature reveal that some scorpion venoms are able to cause malformations and/or harmful effects on the offspring of experimental animals when the dams are inoculated during pregnancy. A paper from Saudi Arabia (13) showed that the venom of $A$. amoreuxi, when injected consecutively from the ninth to the twenty-first day of gestation $(0.2 \mathrm{mg} / \mathrm{kg} / \mathrm{day})$ in dams caused a large number of cases of fetal resorptions, underweight fetuses and skeleton defects. This same paper mentions that the venom of another scorpion species, Buthus minax, inoculated at small and repeated doses, causes skeleton malformation in goats and induces abortion in pregnant women stung by this scorpion.

Scorpion venoms have some effects on uterine contractility. Thus, Buthus occitanus venom was found to contain a bradykinin-potentiating peptide that causes contraction in isolated rat uterine muscle (22), and a toxin $\mathrm{T} 1$ from $T$. serrulatus venom has the same effect in isolated rat uterus (23). The venom of Leiurus quinquestriatus produced a marked increase in the frequency and amplitude of contraction of the rat uterus, and the uterus of pregnant rats seems to be more sensitive to the effect of scorpion venom during early pregnancy (21). However, in an extensive review of the literature between the years of 1966 and 2002, Langley (15) described that no adverse consequences were reported in both mother and fetuses in accidents occurred during pregnancy. Ben Nasr et al. (3) observed that two scorpionenvenomed pregnant patients developed intense pelvic pain and vaginal bleeding but neither maternal and fetal death nor preterm fetal delivery was observed among twelve patients.

In our study, concerning the maternal reproductive performance of the groups of females that had received venom ( $3 \mathrm{mg} / \mathrm{kg}$ ) on GD5 and GD10, we did not observe alterations in the number of corpora lutea. The variation in maternal weight, the uterine weight, and the number of resorptions, implantations, pre-implantation losses, live fetuses and dead fetuses had not been modified either. However, in the group of dams that had received venom on GD10, there was an increase in post-implantation losses. This parameter establishes the relation between the number of embryos that were implanted with the number of embryos that developed normally. Preimplantation losses establish a relation between the numbers of released and 
fecundated eggs and the number of embryos that got implanted. Thus, we can consider that the venom must be acting on the fetal development and not on the implantation of the embryos; otherwise we would also observe alterations in the preimplantation losses and in the total number of implantations.

Blastocyst implantation in the maternal uterus is a process that involves highly coordinated movements in which specific cells of the embryo make contact with a specialized tissue of the mother, the uterus. This coordination involves regulated production of growth factors, cytokines and hormones, for both the embryo and the maternal tissues. At the same time, receptors for these factors must be expressed by the appropriate tissues so as to propagate the implantation signals (4). In most of the studies, the results reveal a higher reduction in the number of implantations than in the number of anatomic malformations, relating this period, above all, to the embryo lethality phenomenon. However, several studies have shown that the primary days of gestation are susceptible to nonlethal damages, leading thus to the generation of malformations (31). For the effects relating to the organogenesis phase, mainly the data obtained for the GD10 group was analyzed. Data from the literature point out this day, on the gestation of rats, to be susceptible to malformations in the eyes, heart, aortic arches, axial skeleton and brain; GD10 also includes possible malformations in the urogenital system and in the palate (20).

Venom administered on GD5 and on GD10 was not capable of producing external malformations in none of the analyzed offspring. Fetal development was not impaired, this fact can also be evidenced by the counting of the centers of ossifications, which did not disclose alterations. The anomalies found, both the skeletal and the visceral ones, had been presented in the experimental groups in amounts and of nature very similar to those presented in the control group, which does not support the hypothesis of the venom teratogenic effect. According to some authors $(14,35)$, spontaneous anomalies and malformations eventually occur in laboratory rats. Thus, it would be evident that this type of occurrence does not have any link with prenatal exposure to the venom. However, the cranial ossification of the fetuses of mothers who received venom on GD10 was slightly affected. A third part of the fetuses, corresponding to $6 / 10$ of the analyzed offspring, presented a slight sinking of the occipital and parietal bones. Probably, this type of effects derives from our treatment. 
In relation to the weight of fetuses, their respective placentas, lung, heart and kidneys, we did not observe significant alterations in none of the analyzed groups. However, we verified that in the groups whose mothers had received venom, an increase in the weight of liver of the offspring occurred, showing that this can be one of the organs affected by the venom. Another study of our laboratory (8) demonstrated an increase in the weight of lungs and placentas of fetuses whose mothers had received smaller venom doses. This leads us to believe that a higher dose does not necessarily lead to an increase in the effect. It may occur or not, independently of the administered dose.

Although the increase in fetal organs weight is not traditionally related to fetal damage, the possibility that the observed result, an increase in liver weight, is a consequence of the venom cannot be ruled out. This effect could be better studied by increasing the used dose on the same date that the present results were obtained.

Many people that were stung by $T$. serrulatus died from pulmonary edema $(11,12)$. The endovenous injection of this venom in rats induces acute lung edema $(11,30)$. Studies on the kinetics of this venom have indicated the lung as an organ that concentrates high levels of this venom on its tissues. Maximum venom levels occurred at $15 \mathrm{~min}$ in the kidney and liver and at 30min in serum, lung, heart and spleen (26).

The histopathological analysis of placentas, kidneys, livers, hearts and lungs of the fetuses reveals tissues with no abnormality when compared to the organs of the pups from the control groups.

Based on the present results, we may not point out whether the observed effects are due to some venom component passing to the offspring or whether it is just an indirect effect caused only in the mother. However, Ismail et al. (13) described that the teratogenic effect of the venom, observed after a prolonged exposition of pregnant rats to $A$. amoreuxi venom, appears to be the result of its metabolic effect and action on body electrolytes of the dams, rather than a direct effect on the fetuses.

In addition, even when trying the most to avoid stress, either by the environmental conditions in which the animals were maintained and treated or by the apparently low maternal toxicity created by the envenomation, the stress is pointed out as a possible hypothesis to explain the obtained results. This fact can be explained by the inevitability of certain procedures such as the injection of the venom that, although at 
a low dose, always causes discomfort to the animals. Also, we cannot rule out the hypothesis that, even causing little effect in the dams, the venom may act in a more incisive way in the offspring, whether by stress generation or by direct action.

As a conclusion, despite all the observed effects, $T$. serrulatus venom does not cause serious deleterious effects in rat offspring.

\section{ACKNOWLEDGEMENTS}

This work was supported by a grant from FAPESP (The São Paulo State Research Foundation) 03/10211-7. This work is part of a Master's Thesis presented by Aline Aparecida Barão Saltão to the Center of Disease Control, SES - SP. 


\section{REFERENCES}

1 ALIVERTI V., BONANOMI L., GIAVINI E., LEONE VG., MARIANI L. The extent of fetal ossification as an index of delayed development in teratogenic studies on the rat. Teratology, 1979, 20, 237-42.

2 BECERRIL B., MARANGONI S., POSSANI LD. Toxins and genes isolated from scorpions of the genus Tityus. Toxicon, 1997, 35, 821-35.

3 BEN NASR H., HAMMAMI TS., REBAI T., BOUAZIZ M., KASSIS M., ZEGHAL KM. Scorpion envenomation symptoms in pregnant women. J. Venom. Anim. Toxins incl. Trop. Dis., 2007, 13, 94-102.

4 CARSON DD., BAGCHI I., DEY SK., ENDERS AC., FAZLEBAS AT., LESSEY BA., YOSHINAGA K. Embryo Implantation. Dev. Biol., 2000, 223, 217-37.

5 CASTLE NA., HAYLETT DG., JENKINSON DH. Toxins in the characterization of potassium channels. Trends Neurosci., 1989, 12, 59-66.

6 CATTERALL WA. Neurotoxins that act on voltage sensitive sodium channels in excitable membranes. Ann. Rev. Pharmacol. Toxicol., 1980, 20, 15-43.

7 COURAUD F., JOVER E. Mechanism of action of scorpion toxins. In: TU TA. Ed. Handbook of natural toxins: Insect poisons, allergens and other invertebrate venoms. New York: Marcel Dekker, 1983, 2, 659-78.

8 CRUTTENDEN K., NENCIONI ALA., BERNARDI MM., DORCE VAC. Reproductive toxic effects of Tityus serrulatus scorpion venom in the rat. Reprod. Toxicol., 2008, submitted.

9 DORCE VAC., SANDOVAL MRL. Brazilian scorpion venoms: pharmacological aspects. Ciên. Cult., São Paulo, 1992, 44, 187-91.

10 DORCE VAC., SANDOVAL MRL. Effects of Tityus serrulatus crude venom on the GABAergic and dopaminergic systems on the rat brain. Toxicon, 1994, 32, 1641-7.

11 FREIRE-MAIA L. Peripheral effects of Tityus serrulatus scorpion venom. J. Toxicol. Toxin Rev., 1995, 14, 423-35.

12 ISMAIL M. The scorpion envenoming syndrome. Toxicon, 1995, 33, 825-58.

13 ISMAIL M., ELLISON AC., TILMISANY AK. Teratogenicity in the rat of the venom from the scorpion Androctonus amoreuxi. Toxicon, 1983, 21, 177-89.

14 KIMMEL CA., WILSON JG. Skeletal deviations in rats: malformations or variations? Teratology, 1973, 8, 309-16.

15 LANGLEY RL. A review of venomous animals and stings in pregnant patients. Wilderness Environ. Med., 2004, 15, 207-15. 
16 LIMA ME., MARTIN-EAUCLAIRE MF. The toxins purified from Tityus serrulatus (Lutz and Mello) venom. J. Toxicol. Toxin Rev., 1995, 14, 457-81.

17 LOURENÇO WR., CLOUDSLEY-THOMPSON JL., CUELLAR O., VON EICKSTEDT VRD., BARRAVIERA B., KNOX MB. The evolution of scorpionism in Brazil in recent years. J. Venom. Anim. Toxins, 1996, 2, 121-34.

18 LUCAS SM., MEIER J. Biology and distribution of scorpions of medical importance. In: MEIER J., WHITE J. Eds. Handbook of clinical toxicology of animal venoms and poisons. New York: CRC Press, 1995: 205-19.

19 MAgAlHÃES MM., PEREIRA MES., AMARAL CFS., REZENDE NA., CAMPOLINA D., BUCARETCHI F., GAZZINELLI RT., CUNHA-MELO JR. Serum levels of cytokines in patients envenomed by Tityus serrulatus scorpion sting. Toxicon, 1999, 37, 1155-64.

20 MANSON J., KANG YS. Test methods for assessing female reproductive and developmental toxicology. In: HAYES AW. Ed. Principles and Methods of Toxicology. New York: Raven Press, 1989: 311-59.

21 MAREI ZA., IBRAHIM SA. Stimulation of rat uterus by venom from the scorpion $L$. quinquestriatus. Toxicon, 1979, 17, 251-8.

22 MEKI AR., NASSAR AY., ROCHAT H. A bradykinin-potentiating peptide (peptide $\mathrm{K} 12$ ) isolated from the venom of Egyptian scorpion Buthus occitanus. Peptides, 1995, 16, 1359-65.

23 MENDONÇA M., LUZ MM., FREIRE-MAIA L., CUNHA-MELO JR. Effect of scorpion toxin from Tityus serrulatus on the contraction of the isolated rat uterus. Toxicon, 1995, 33, 355-61.

24 OSMAN OH., ISMAIL M., EL-ASMAR MF., IBRAHIM SA. Effect on the rat uterus of the venom from the scorpion Leiurus quinquestriatus. Toxicon, 1972, 10, 363-6.

25 POSSANI LD., FLETCHER PL., FLETCHER M., MOCHCA-MORALES J., LUCAS SM., CORONAS FV., ALAGON AC., MARTIN BM. Structural and functional characteristics of toxins purified from the venom of the Brazilian scorpion Tityus serrulatus Lutz and Mello. Mem. Inst. Butantan, 1992, 54, 35-52.

26 REVELO MP., BAMBIRRA EA., FERREIRA AP., DINIZ CR., CHAVEZOLORTEGUI C. Body distribution of Tityus serrulatus scorpion venom in mice and effects of scorpion antivenom. Toxicon, 1996, 34, 119-25. 
27 ROCHAT H., BERNARD P., COURAUD F. Scorpion toxins: chemistry and mode of action. In: CECCARELLI B., CLEMENTI F. Eds. Neurotoxins: Tools in Neurobiology. New York: Raven Press, 1979: 325-34.

28 RODRIGUEZ DE LA VEGA RC., POSSANI LD. Current views on scorpion toxins specific for $\mathrm{K}^{+}$-channels. Toxicon, 2004, 43, 865-75.

29 RODRIGUEZ DE LA VEGA RC., POSSANI LD. Overview of scorpion toxins specific for $\mathrm{Na}^{+}$channels and related peptides: biodiversity, structure-function relationships and evolution. Toxicon, 2005, 46, 831-44.

30 ROSSI MA., FERREIRA AL., PAIVA SM. Fine structures of pulmonary changes induced by Brazilian scorpion venom. Arch. Pathol., 1974, 97, 284-8.

31 RUTLEDGE JC. Developmental toxicity induced during early stages of mammalian embryogenesis. Mutat. Res., 1997, 396, 113-27.

32 SANDOVAL MRL., DORCE VAC. Behavioral and electroencephalographic effects of Tityus serrulatus scorpion venom in rats. Toxicon, 1993, 31, 205-12.

33 SANDOVAL MRL., DORCE VAC. The envenomation by Tityus serrulatus scorpion venom: age and sex influence. Mem. Inst. Butantan, 1993, 55, 5-10.

34 STAPLES RE., SCHENELL VL. Refinements in rapid clearing technique in the KOH-alizarin red S method for fetal bone. Stain Technol., 1964, 39, 61-3.

35 SZABO KT. Congenital malformations in laboratory and farm animals. San Diego: Academic Press, 1989.

36 TAN PT., RANGANATHAN S., BRUSIC V. Deduction of functional peptide motifs in scorpion toxins. J. Pept. Sci., 2006, 12, 420-7.

37 VON EICKSTEDT VR., RIBEIRO LA., CANDIDO DM. Evolution of scorpionism by Tityus bahiensis (Perty) and Tityus serrulatus (Lutz and Mello) and geographical distribution of the two species in the state of São Paulo, Brazil. J. Venom. Anim. Toxins, 1996, 2, 92-105.

38 WILSON JG. Methods for administering agents and detecting malformation in experimental animal. In: WILSON JC., WARKANY J. Eds. Teratology: principles and techniques. Chicago: University of Chicago Press, 1965. 